\title{
Loon Nest Viability Model: A Performance Indicator for Improving Water-Level Regulation of Large Water Bodies
}

\author{
Marianne Bachand1, Julien-Hénault-Richard ${ }^{2}$, Sylvain Martin'1, Steve K. Windels ${ }^{3}$, Jean Morin'1 \\ ${ }^{1}$ Meteorological Service of Canada, Environment and Climate Change Canada, Québec, Canada \\ ${ }^{2}$ Département de biologie \& Centre d'études nordiques, Université Laval, Québec, Canada \\ ${ }^{3}$ Voyageurs National Park, International Falls, USA \\ Email: marianne.bachand@canada.ca
}

How to cite this paper: Bachand, M., Julien-Hénault-Richard, Martin, S., Windels, S.K. and Morin, J. (2018) Loon Nest Viability Model: A Performance Indicator for Improving Water-Level Regulation of Large Water Bodies. Natural Resources, 9, 1-16. https://doi.org/10.4236/nr.2018.91001

Received: December 20, 2017

Accepted: January 21, 2018

Published: January 24, 2018

Copyright $\odot 2018$ by authors and Scientific Research Publishing Inc. This work is licensed under the Creative Commons Attribution International License (CC BY 4.0).

http://creativecommons.org/licenses/by/4.0/

\begin{abstract}
Rule curves dictating target water levels for management have been implemented in several water bodies in North America over the last 70 years or more. Anthropogenic alterations of water levels are known to affect several components of wetland ecosystems. Evaluating the influence of rule curves on biological components with simple performance indicators could help harmonize water level management with wetland integrity. We assessed the potential of using the probability of common loon nest viability as a performance indicator of long-term impacts of rule curves on nesting wetland birds. We analyzed the outcome of rule curves on the probability of loon nest viability in Rainy Lake and Namakan Reservoir, 2 regulated water bodies located along the Ontario-Minnesota border. The analysis was focused on 4 hydrological time series between 1950 and 2013: 2 sets of time series simulating rule curves used to manage the water bodies in the past decades (referred to as the 1970RC and 2000RC), one of the historical measured water levels, and one of computed natural water levels. The probability of loon nest viability under the 1970RC was $2 \times$ higher than under natural conditions in both water bodies. The probability was also $2 \times$ higher under the 2000RC than under the 1970RC in the Namakan Reservoir but not in Rainy Lake. The rule curves generally improved conditions for nesting loons in both water bodies. The presented performance indicator can be used to evaluate future rule curves before they are implemented in the Rainy-Namakan or other similar systems.
\end{abstract}

\section{Keywords}

Gavia immer, Namakan Reservoir, Nest Viability, Performance Indicator, Rainy Lake, Rule Curves, Water Level 


\section{Introduction}

Water levels (WL) in lakes and reservoirs naturally fluctuate according to hydrology and climate. The magnitude of WL variations is dependent on the morphology of water bodies and their watershed [1], and climatic conditions such as rainfall, snow- and ice-melt, wind speed, and air temperature (e.g. [2] [3]). Concordantly, natural WL variations have shaped the life cycles of numerous organisms which evolved under their influence [4] [5].

Anthropogenic infrastructures used for flood management, hydroelectric power, or to provide suitable conditions for navigation can lead to significant changes in annual and inter-annual WL variations that may contrast sharply with natural conditions [6]. Multiple characteristics of a WL regime, such as its amplitude, timing, and rate of variation, are often impacted by WL regulation [5], thereby resulting in changes to the biological aspects of the ecosystem, such as its suitability as a fish spawning habitat [7] or the distribution of wetlands [8].

Rule curves (RC) are guidelines dictating target WL of a managed water body for different times of year. They are used to determine the timing and magnitude of water supply and releases according to a management plan. In recent decades, ecosystem integrity has received increasing consideration when evaluating impacts of RC (e.g. [9] [10]). Given the large number of species present in wetland ecosystems, evaluating the impacts of RCs on all species is unrealistic. Instead, one often focuses on a smaller selection of key species to develop performance indicators as a practical means to assess RC impacts [11] [12] [13].

Wetland birds are sensitive to fluctuating WL, natural or anthropogenic, which can affect their habitat for foraging, nesting, and predator avoidance [14] [15]. The common loon (Gavia immer), a symbol of the northern wilderness, is a recognized indicator of wetland ecosystem health because of its high trophic position, limited dispersal ability, and slow replacement rate [16]. Common loons are poorly adapted to moving on land and must therefore build their nests close to water to facilitate access, thereby exposing their nests to the consequences of large WL fluctuations [17] [18]. There are two ways by which WL fluctuation may cause nesting failure: increasing WL during the nesting season may cause nest flooding, while decreasing WL can result in nest abandonment or increased predation risk for eggs or chicks [19]. These features therefore make the common loon a sensitive performance indicator to assess the impacts of different RC on nesting wetland birds.

Studies have examined the role of artificial WL variations on loon population dynamics in North America (e.g. [19] [20] [21] [22]). These studies considered several explanatory variables (e.g. amplitude of water level variations, predation, climatic regime, etc.) linking loon nesting success to the environment in a specific area during a few years (e.g. [19] [23]). The objective of the present study was to develop a simple decision-support model based on one physical variable that can be used to evaluate the impacts of different RC on common loon nest viability over a 60 -year period. The model estimates the effects of lake-wide WL 
variation during the nesting season on the probability of loon nest viability. The goal of this model is to provide information on the general suitability of past, present, and future WL variations for wetland birds that nest on or near the water.

\section{Material and Methods}

\subsection{Study Area}

The study area was located along the Canada-USA border and covered 2 main regulated water bodies: Rainy Lake $\left(48^{\circ} 38^{\prime} 60^{\prime \prime} \mathrm{N}-93^{\circ} 17^{\prime} 60^{\prime \prime} \mathrm{W}\right)$ and Namakan Reservoir $\left(48^{\circ} 30^{\prime} 18^{\prime \prime} \mathrm{N}-92^{\circ} 38^{\prime} 13^{\prime \prime} \mathrm{W}\right)$, parts of which are within Voyageurs National Park (VNP; Figure 1). Namakan Reservoir, in this study, includes 4 interconnected lakes (Namakan, Kabetogama, Sand Point, and Crane), which were considered as a single entity with the same WL for this study. Rainy Lake covers $932 \mathrm{~km}^{2}$, has $405 \mathrm{~km}$ of shoreline and around 340 islands, whereas Namakan Reservoir covers $260 \mathrm{~km}^{2}$, has $665 \mathrm{~km}$ of shoreline and 375 islands. The hundreds of small islands combined with numerous wetlands and deeper channels offer a diversity of habitat suitable to breeding loons [24]. Rainy Lake has been regulated since 1909 at the International Falls dam, while WL in Namakan Reservoir has been controlled since 1914 by dams at Kettle Falls and Squirrel Falls (Figure 1).

\subsection{Historical Rule Curves}

Water levels of these water bodies were controlled by private companies managing

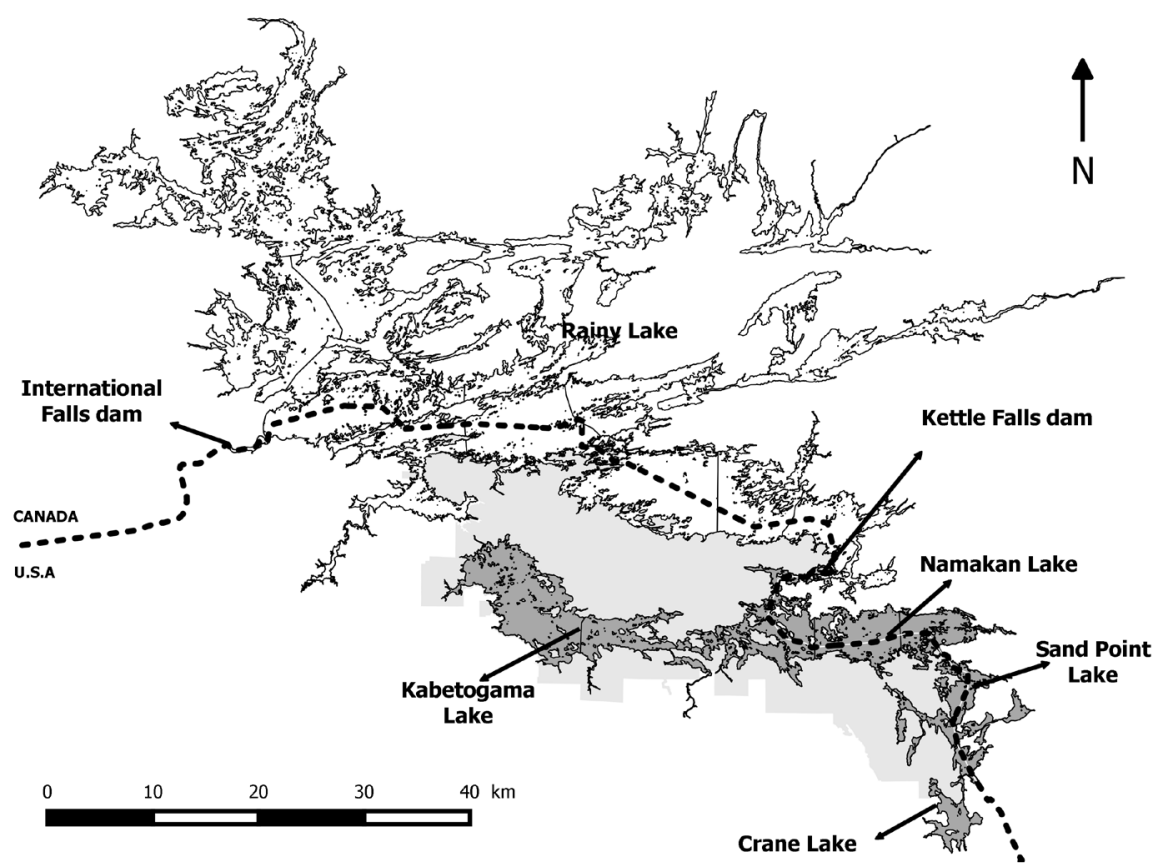

Figure 1. Rainy Lake (white) and Namakan Reservoir (dark grey) that includes Namakan, Kabetogama, Sand Point, and Crane lakes along the Canada-USA border (black dashed line) and Voyageurs National Park (light gray). 
the dams from their construction in the early 1900s to 1949. After 1949, the International Joint Commission (IJC) implemented RC dictating target WL that sought to balance hydropower production and interest of other groups, such as the State of Minnesota, the Province of Ontario, First Nations, and riparian land owners [25]. One of the RC, the 1970RC, emphasized the need of maintaining a minimum flow in the Rainy River downstream of Rainy Lake by prescribing minimum outflows from the lakes. More recently, the 2000RC aimed to balance interests upstream and downstream of the system, including environmental concerns, hydropower production, flooding avoidance, boat navigation, and water quality improvement in Rainy River ([25]; Figure 2).

\subsection{Water Level Time Series}

We used 4 different WL time series to evaluate the impact of RC on the viability of common loon nests. These time series were built for each water body in quartermonthly (QM) time-steps covering the 1950 to 2012 period [26]. The first time series is called "MEASURED" and is based on daily mean water level measured at several different gauging stations on the lakes (see [27] for more details). In addition, we used 3 simulated WL time series reflecting different management plans. The second time series is called "NATURAL" and simulates natural WL in the absence of management. The third and fourth are called "1970RC" and "2000RC" and simulate WL that would have occurred under the 1970RC or 2000RC, respectively, had they been applied for the entire 60 years period (1952 to 2012).

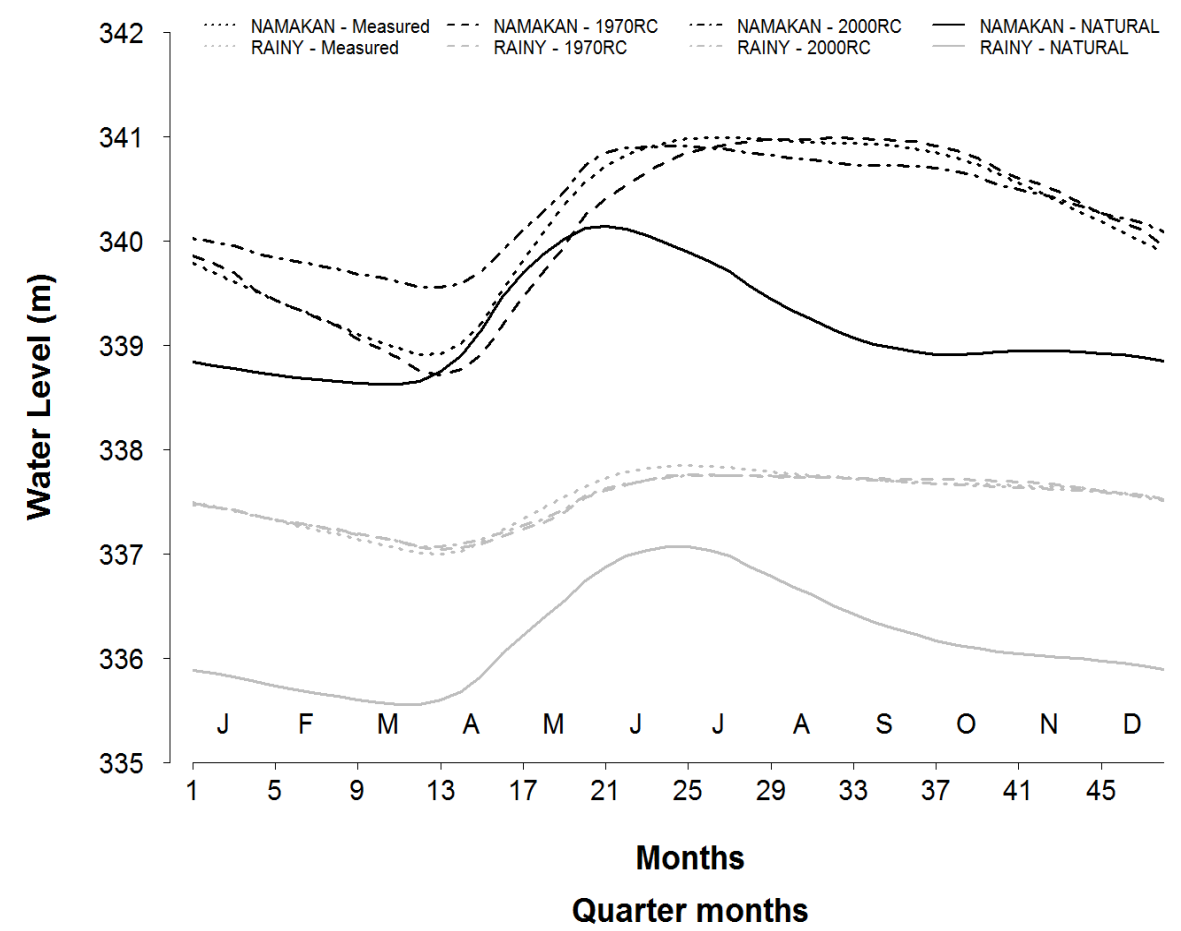

Figure 2. Mean quarter monthly (QM) water levels of Rainy Lake (gray lines), and Namakan Reservoir (black lines) according to different rule curves (RC) between 1950 and 2012. See [27] for data sources and methods 


\subsection{Model Conception}

\subsubsection{Common Loon Nesting Season}

Common loons reach their nesting territories soon after ice-out. Nesting typically occurs between May and July, attaining maximum intensity between June and mid-July [19] [28]. In VNP, nest observations made by [19] between 2004 and 2006 showed that nesting starts between the $18^{\text {th }}$ and $27^{\text {th }} \mathrm{QM}$, with a peak between the $20^{\text {th }}$ and $22^{\text {nd }} \mathrm{QM}$ (Table 1 ). As the timing of nest initiation varies annually according to meteorological conditions, dates reported in [19] were used to assess the relationship between ice-out and nest initiation dates in Rainy Lake and Namakan Reservoir. We estimated that peak nest initiation (i.e. the date at which $50 \%$ of the nests were initiated) occurred approximately 6 QM after ice-out and the nest initiation period began $3 \mathrm{QM}$ after ice-out. We validated these estimates by finding similar timing between 48 loon nest initiation dates recorded between 1965 and 2009 in Algonquin Provincial Park, Ontario [28] [29] and ice-out dates of nearby Opeongo Lake. Field observations from [19] in VNP and a study from [23] also enabled the calculation of the mean duration of nesting period ( $8 \mathrm{QM} \approx 60$ days) and the percentage of nests initiated in each $\mathrm{QM}$, on average (Table 1).

According to [19], nest construction takes several days (1 QM); but replacement nests can be quickly built within a few days. Moreover, egg laying spans over about 1 QM, while incubation lasts approximately 4 QM ( $\approx 30$ days). During incubation, WL must remain relatively stable to avoid nest flooding or stranding while eggs are present. In the event of nest failure, loons will attempt re-nesting up to two times within a breeding season [19] [24].

When a nest fails due to flooding or abandoned because of WL variations, $48 \%$ of loon pairs have attempted to re-nest in VNP. Ultimately, $14 \%$ of breeding pairs that were also unsuccessful in the second attempt attempted a third nest [19]. Most observations of loons building nests in July have occurred after the first nest failed [24] and nest building is rarely observed in August [17] [30].

Table 1. Mean percentage of common loon nests initiated in each quarter month (QM) following ice-out, based on data recorded from 2004-2006 in Voyageurs National Park, MN, USA [19].

\begin{tabular}{cc}
\hline QM after ice-out & \% of nests initiated \\
\hline 3 & 7.8 \\
4 & 13.6 \\
5 & 16.7 \\
6 & 17.4 \\
7 & 16.2 \\
8 & 13.4 \\
9 & 9.3 \\
10 & 4.5
\end{tabular}


Given 1) the period of nest initiation identified by [19] (between the $18^{\text {th }}$ and the $27^{\text {th }} \mathrm{QM}$ of the year); 2) the possibility that an unsuccessful breeding pair can attempt to re-nest until late-July; 3) the relation we identified between nest initiation and ice-out dates (begins $3 \mathrm{QM}$ after ice-out and peaks $6 \mathrm{QMs}$ after ice-out); $4)$ and the time required for egg laying (1 QM) and incubation (4 QMs), we determined that the full extent of the potential nesting period ranged from the $3^{\text {rd }}$ $\mathrm{QM}$ after ice-out to the $33^{\text {rd }} \mathrm{QM}$ of the year.

\subsubsection{Probability of Loon Nest Viability (PLNV)}

To assess the impacts of WL time series on common loon nesting success, we developed a single variable model predicting the probability of loon nest viability (PLNV) as a function of WL variation during the nesting season. The PLNV is based on a nest suitable to lay and incubate eggs and does not estimate direct nesting success (i.e., the number of hatched chicks). Any decreases in nest viability according to WL variations is, however, assumed to result in decreased nesting success, as nest viability is essential for nesting success.

We thus identified thresholds beyond which WL variations may affect loon nest viability. It has been suggested that loon nesting conditions are optimal when WL do not increase by more than $0.15 \mathrm{~m}$ or decrease by more than $0.30 \mathrm{~m}$ during the nesting period [31]. As such, WL variations within these values ( -0.30 to $0.15 \mathrm{~m}$ from WL at nesting QM) should not affect loon nest viability (i.e., PLNV = 1; Figure 3). On the other hand, [23] suggested that a WL increase of $1.00 \mathrm{~m}$ during the entire nesting season $(8 \mathrm{QM})$ decreases the probability of nesting success by about $50 \%$, while a WL decrease of $1.00 \mathrm{~m}$ decreases the probability of nesting success by about $20 \%$. Therefore, we made the assumption that WL increases are two times more harmful to loon nest viability than WL decreases of the same amplitude. Because data collected by [19] in the RainyNamakan system revealed 6 cases of loons building up the nest rim by 0.30 to $0.44 \mathrm{~m}$ above the water surface after nest initiation to prevent flooding, we assumed that a WL increase of $0.44 \mathrm{~m}$ or greater would result in all nests being flooded, giving a PLNV of 0 in such a scenario (Figure 3). A WL decrease greater than $0.88 \mathrm{~m}$ (i.e., twice the maximum increase of $0.44 \mathrm{~m}$ ) would also yield a PLNV of 0 (Figure 3). Finally, we estimated the PLNV for WL variations within identified thresholds (i.e., between -0.88 to $-0.30 \mathrm{~m}$ or between 0.15 to $0.44 \mathrm{~m}$ from WL at nest initiation), by assuming that it would vary linearly between 0 and 1 (Figure 3; Equation (1), and Equation (2)).

$$
\begin{aligned}
& \text { PLNV }_{\text {increase }}=-4.000 \mathrm{x}+1600 \\
& \text { PLVN }_{\text {decrease }}=2000 \mathrm{x}+1.600
\end{aligned}
$$

For the duration of the nesting period, the PLNV in each QM was multiplied by the percentage of loon nests presumed to be active during this QM (Table 1). Based on known nesting and incubation duration [27], nests were considered active for at least $5 \mathrm{QMs}$ after nest initiation. In cases of failure, re-nestings were attempted until the $27^{\text {th }} \mathrm{QM}$ (i.e., the $3^{\text {rd }}$ week of July). 


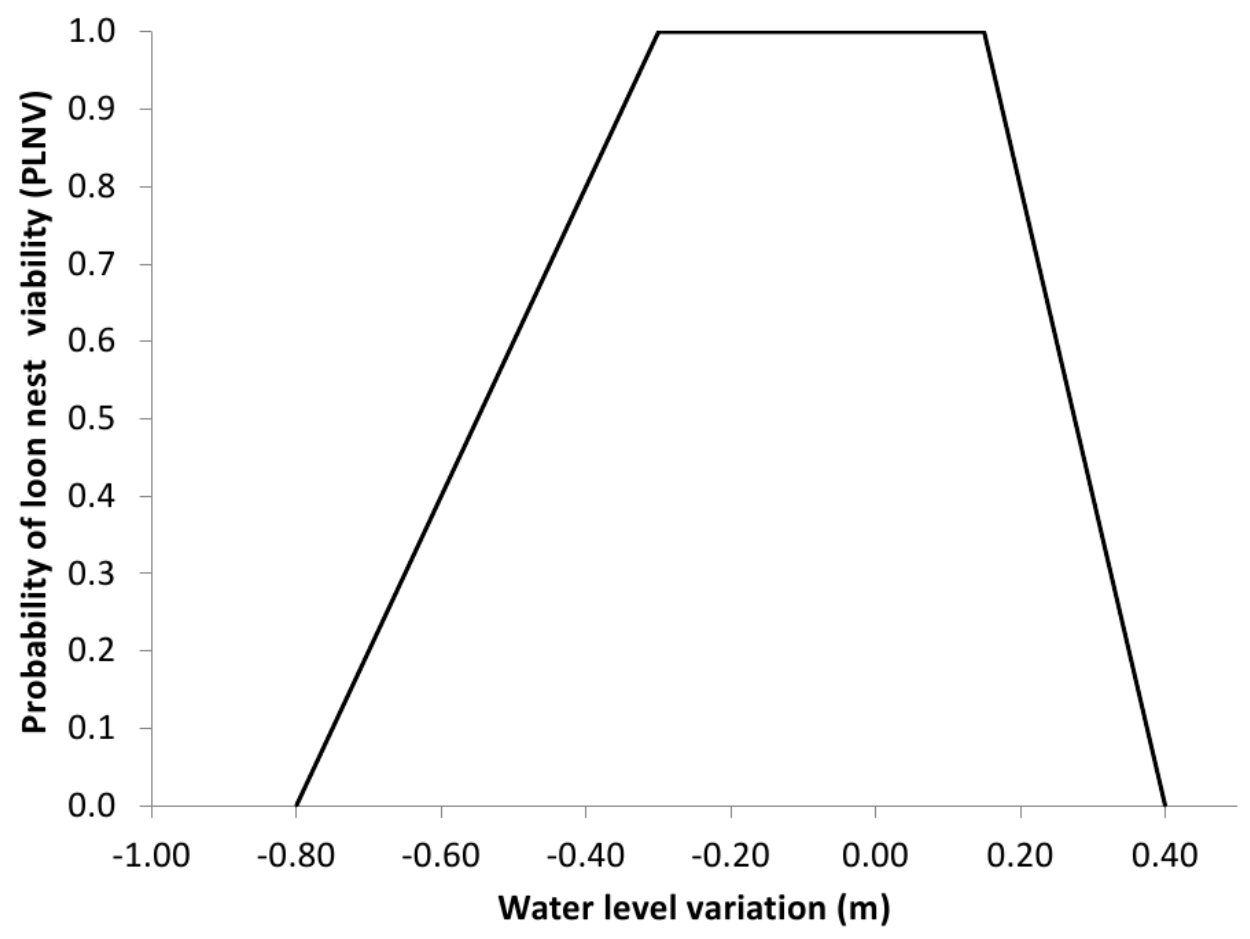

Figure 3. Probability of loon nest viability (PLNV) according to water level variation between nest initiation and the end of the nesting period. PLNV between 0.15 to $0.44 \mathrm{~m}$ of WL increase from WL at nest initiation was estimated with Equation (1) when PLNV between -0.88 to $-0.30 \mathrm{~m}$ of WL decrease was estimated with Equation (2).

In addition to assessing the influence of WL variations on PLNV we also considered the timing at which, meaning which $\mathrm{QM}$, theses variations occurred to obtain a more complete picture of their influence on loon nest viability.

\subsubsection{Validation}

Model validation was done by comparing predicted PLNV with nest status observed by [19] in 2004-2006 when they checked on incubating loons every 3 to 5 days throughout the nesting seasons to monitor nest status. Nests were classified as successful or failed. Failed nests were classified as predated, flooded, stranded or unknown. Since our model only considers the impact of WL variations, we only kept nests classified as successful, flooded or stranded to calculate an "observed" PLVN for each year in Rainy Lake and Namakan Reservoir.

\subsubsection{Statistical Tests}

The MEASURED time series can be split into 3 periods with different WL management: 1950-1970, before the implementation of the 1970RC; 1970-2000, when WL were managed according to the 1970RC; and 2000-2012, when they were managed according to the 2000RC. We calculated the average PLNV during each period before comparing them with t-tests. We used a second set of (paired) $\mathrm{t}$-tests to compare the PLNV of the 3 simulated time series (1970RC, 2000RC, and NATURAL). We adjusted the p-values for multiple comparisons with the Bonferroni correction. 


\section{Results}

\subsection{Nesting Success Validation}

Using data from [19], we were able to compare observed nesting success between 2004 and 2006 with simulated PLNV obtained from the model. Although the model simulates loon nest viability according to water-level variations and not nesting success, both should follow a similar trend. Predicted PLNV and observed percentages of successful nests followed similar trends in each water body (Table 2); both showed little inter-annual variability in Namakan Reservoir, and both were higher in 2004 and 2006 than in 2005 in Rainy Lake. Both lakes are strongly influenced by the same seasonal fluctuations in precipitation, but because water regulation capacity is somewhat limited, WL variations tend to occur during the same period in both lakes. However, 2005 was different in that Rainy Lake experienced a larger WL fluctuation than Namakan Reservoir during the nesting period, which was more detrimental to loon nesting success [19].

\subsection{Probability of Loon Nest Viability According to the MEASURED Water Level Series}

With the implementation of the 1970RC, PLNV seemed to increase in Rainy Lake (t: -1.366; p-value corrected: 0.548) and decrease in Namakan Reservoir ( $\mathrm{t}$ : 1.769; p-value corrected: 0.260) but not significantly (Table 3 and Figure 4) while similar PLNV were obtained in Rainy Lake (t: 1.965; p-value corrected: 0.201 ) and Namakan Reservoir (t: -2.410; p-value corrected: 0.068) with the implementation of the 2000RC. These temporal variations were, however, not statistically significant once the Bonferroni correction was applied (Table 4).

Table 2. Predicted and observed probabilities of loon nest viability (PLNV) in 2004-2006 in Rainy Lake and Namakan Reservoir, Voyageurs National Park, MN, USA.

\begin{tabular}{ccccc}
\hline \multirow{2}{*}{ Year } & \multicolumn{2}{c}{ Namakan Reservoir } & \multicolumn{2}{c}{ Rainy Lake } \\
\cline { 2 - 5 } & Predicted PLNV & Observed nest success & Predicted PLNV & Observed nest success \\
\hline 2004 & 0.90 & 0.70 & 0.99 & 0.59 \\
2005 & 0.90 & 0.67 & 0.77 & 0.36 \\
2006 & 0.86 & 0.73 & 0.95 & 0.55 \\
\hline
\end{tabular}

Table 3. Mean (SD) probability of loon nest viability (PLNV) determined with the MEASURED water level time series during 3 periods of different water management rules. (1952-1970: water levels before the implementation of the 1970RC; 1970-2000: water levels managed according to the 1970RC; 2000-2012: water levels managed according to the 2000RC).

\begin{tabular}{|c|c|c|c|c|c|c|}
\hline \multirow{2}{*}{ Water body } & \multicolumn{2}{|c|}{$\underline{1952-1970}$} & \multicolumn{2}{|c|}{$\underline{1970-2000}$} & \multicolumn{2}{|c|}{$\underline{2000-2012}$} \\
\hline & PLNV & SD & PLNV & $\mathrm{SD}$ & PLNV & SD \\
\hline Namakan Reservoir & 0.71 & 0.32 & 0.54 & 0.27 & 0.72 & 0.24 \\
\hline Rainy Lake & 0.82 & 0.19 & 0.89 & 0.14 & 0.72 & 0.30 \\
\hline
\end{tabular}


Table 4. Results from t-tests comparing the estimated probability of loon nest viability (PLNV) for the MEASURED water level time series during the periods of different water-level management rules between 1952 and 2012 (1952-1970: before the implementation of the 1970RC; 1970-2000: regulated according to the 1970RC; 2000-2012: regulated according to the $2000 \mathrm{RC}$ ).

\begin{tabular}{cccccc}
\hline Water body & Comparison & t & df & p-value & p-value corrected \\
\hline Namakan Reservoir & $1952-1970$ vs 1970-2000 & 1.769 & 31.081 & 0.087 & 0.260 \\
& $1952-1970$ vs 2000-2012 & -0.345 & 29.955 & 0.732 & 1.000 \\
& $1970-2000$ vs 2000-2012 & -2.410 & 28.538 & 0.023 & 0.068 \\
\multirow{2}{*}{ Rainy Lake } & $1952-1970$ vs 1970-2000 & -1.366 & 28.574 & 0.183 & 0.548 \\
& $1952-1970$ vs 2000-2012 & 1.018 & 21.094 & 0.320 & 0.961 \\
& $1970-2000$ vs 2000-2012 & 1.965 & 15.931 & 0.057 & 0.201 \\
\hline
\end{tabular}

A) Rainy Lake

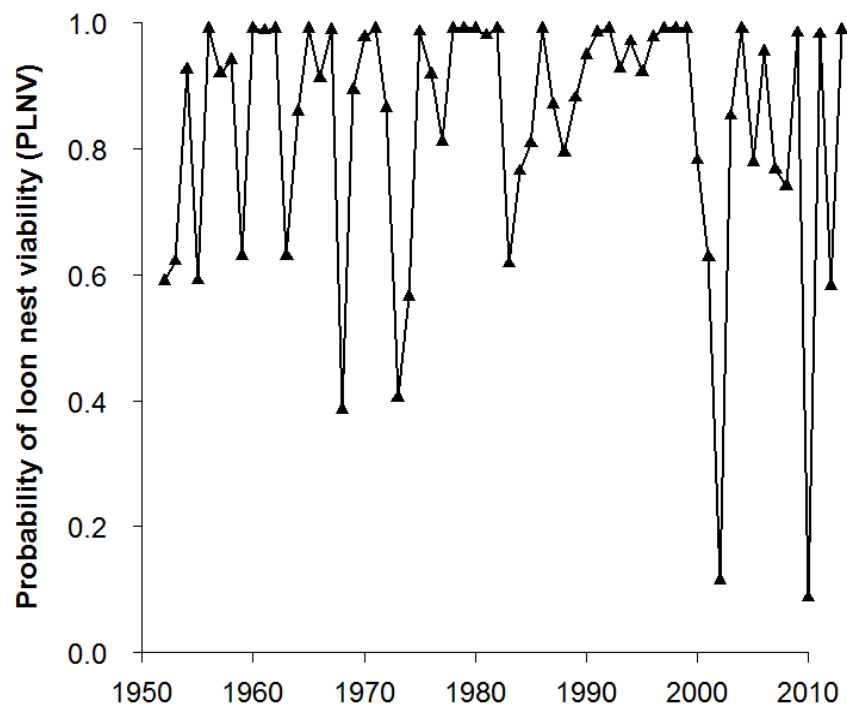

B) Namakan Reservoir

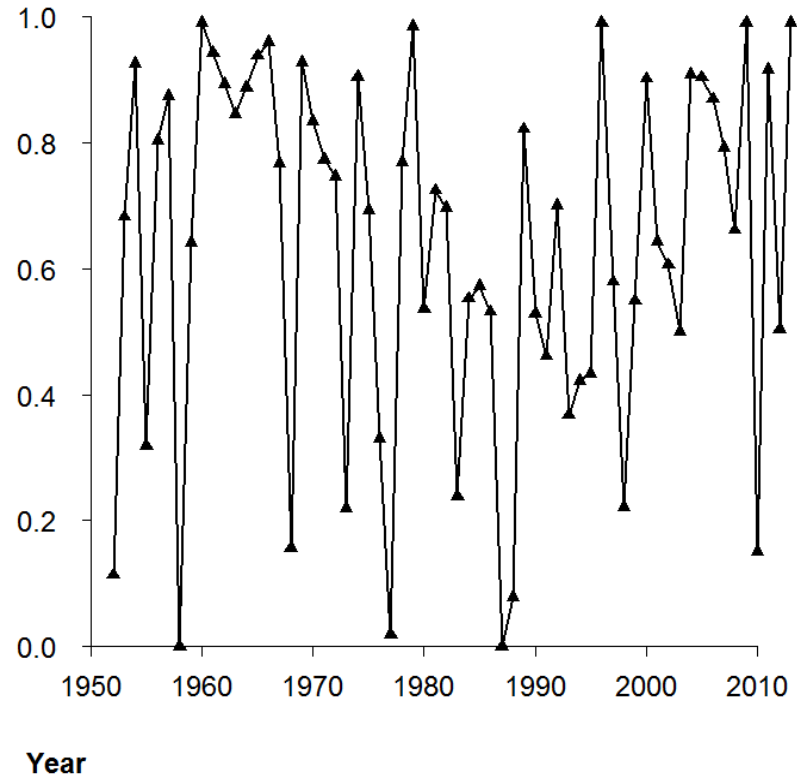

Figure 4. Probability of loon nests viability (PLNV) in (A) Rainy Lake and (B) Namakan Reservoir from 1952 to 2012 calculated for the MEASURED water level time series.

\subsection{Probability of Loon Nest Viability According to Simulated Water Level Time Series}

The 1970RC time series ( $\mathrm{t}$ : -9.488 ; p-value corrected: <0.001) and the 2000RC time series ( $\mathrm{t}$ : 9.556 ; $\mathrm{p}$-value corrected: $<0.001)$ significantly increased and stabilized the PLNV in Rainy Lake compare to the NATURAL time series (Table 5 and Figure 5). In Namakan Reservoir, this is only true for 2000RC ( $\mathrm{t}$ : -9.369 ; p-value corrected: <0.001), as the mean PLNV of the 1970RC was not significantly different ( $\mathrm{t}$ : -1.267 ; p-value corrected: 0.630 ) from the mean PLNV of the NATURAL time series (Table 6). As such, the lowest PLNV would have occurred under the NATURAL time series in both water bodies, while highest PLNV would have occurred under the 2000RC in Namakan Reservoir and no 
significant differences were found between the 1970RC and 2000RC ( $\mathrm{t}:-1.449$; p-value corrected: 0.458) time series in Rainy Lake (Table 5, Table 6 and Figure $5)$.

Table 5. Mean (SD) predicted probabilities of loon nest viability (PLNV) under different water level management regimes between 1952 and 2012, in Rainy Lake and Namakan Reservoir, Voyageurs National Park, MN, USA.

\begin{tabular}{cccccccc}
\hline & \multicolumn{2}{c}{$\underline{1970 R C}$} & \multicolumn{2}{c}{ 2000RC } & \multicolumn{2}{c}{ NATURAL } \\
\cline { 2 - 7 } Water body & PLNV & SD & PLNV & SD & PLNV & SD \\
\hline Namakan Reservoir & 0.50 & 0.29 & 0.86 & 0.18 & 0.42 & 0.314 \\
Rainy Lake & 0.85 & 0.17 & 0.86 & 0.17 & 0.48 & 0.30 \\
\hline
\end{tabular}

Table 6. Results from multiple paired t-tests comparing the time series of estimated probability of loon nest viability (PLNV).

\begin{tabular}{cccccc}
\hline Water body & Comparison & $\mathbf{t}$ & $\mathbf{d f}$ & p-value & p-value corrected \\
\hline Namakan Reservoir & NATURAL vs 1970RC & -1.267 & 60 & 0.210 & 0.630 \\
& NATURAL vs 2000RC & -9.369 & 60 & $<0.001$ & $<0.001$ \\
& 1970RC vs 2000RC & -12.800 & 60 & $<0.001$ & $<0.001$ \\
Rainy Lake & NATURAL vs 1970RC & -9.488 & 60 & $<0.001$ & $<0.001$ \\
& NATURAL vs 2000RC & -9.556 & 60 & $<0.001$ & $<0.001$ \\
& 1970RC vs 2000RC & -1.449 & 60 & 0.153 & 0.458
\end{tabular}

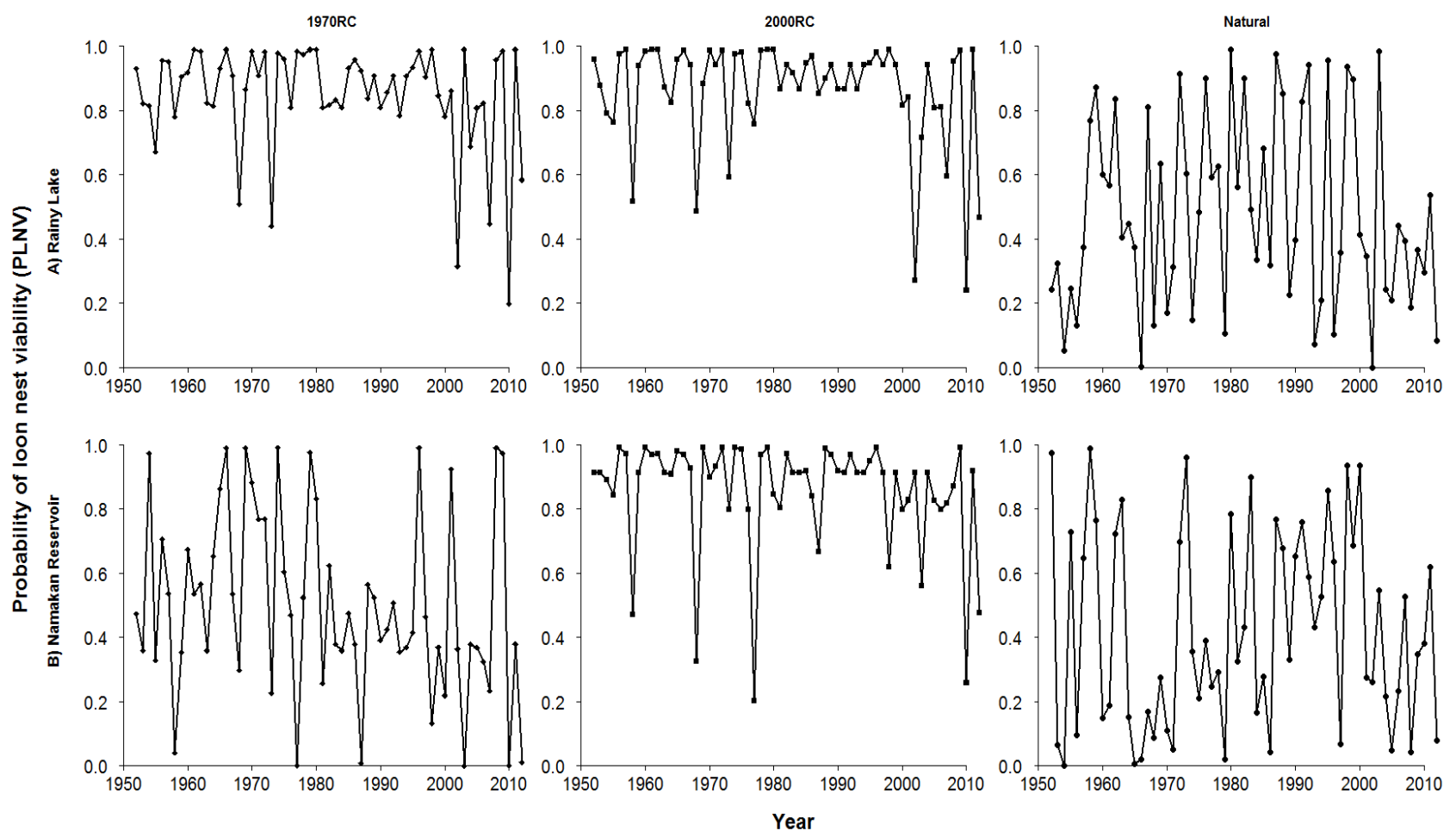

Figure 5. Probability of loon nests viability (PLNV) in (A) Rainy Lake and (B) Namakan Reservoir from 1952 to 2012 calculated for the different simulated water level time series. 


\subsection{Probability of Loon Nest Viability According to the QM of Nest Initiation}

Our model suggests that under natural conditions, PLNV was relatively stable but low regardless of the QM of nest initiation. Nevertheless, PLNV under the NATURAL time series appears higher for nests initiated during the first half of the breeding season, particularly in Rainy Lake (Figure 6). The situation was different under regulated WL, where PLNV were lower early in the nesting season, and then increased later in the nesting season (Figure 6). Causes of nest failure were also different between NATURAL and both regulated time series. Under natural conditions, nest failures were caused by decreasing WL about $65 \%$ of the time. Under regulated WL however, nest failures were caused by increasing WL about $70 \%$ of the time. As it was the case for annual PLNV, the PLNV of nests initiated in each QM were similar for all regulated WL series in Rainy Lake, while the 2000RC provided the most suitable conditions for all nests, regardless of the initiation QM, in Namakan Reservoir. Relatively high PLNV (>0.70) were usually reached by the $4^{\text {th }} \mathrm{QM}$ after ice-out in Rainy Lake
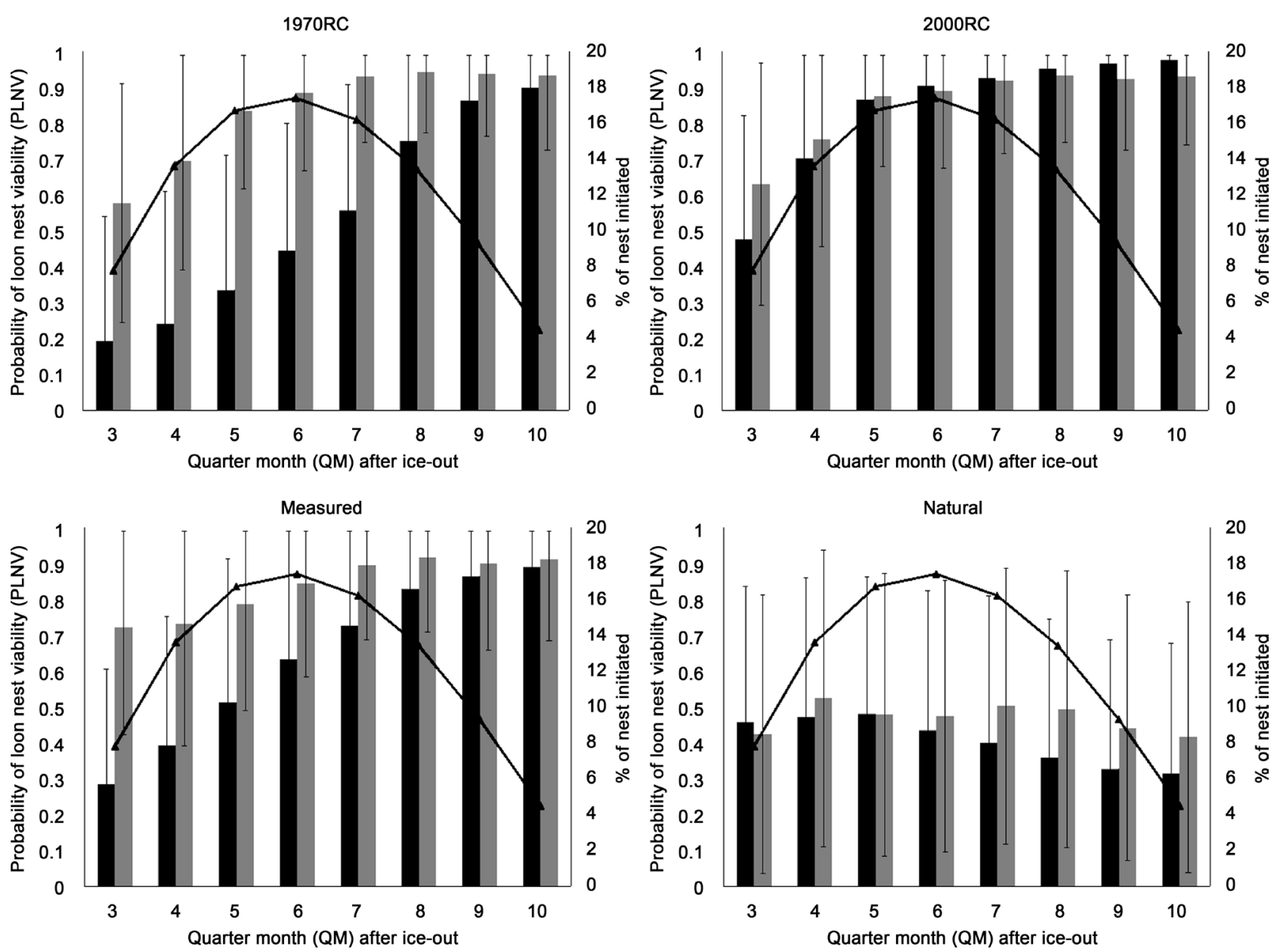

Figure 6. Mean (SD) probability of loon nest viability (PLNV) for nests initiated during different quarter months (QM) after ice-out, for each water level series, between 1952 and 2012. Gray bars: Namakan Reservoir. Black bars: Rainy Lake. Black line: percentage of nests initiated during each quarter month. 
and Namakan Reservoir since the implementation of the 2000RC.

\section{Discussion}

Predicted PLNV and observed percentages of successful nests had similar trends between 2004 and 2006. This suggests that the model we developed was able to predict the relative differences in PLNV among year based on WL variations. Besides the common loon, this model could be adapted to be used as a performance indicator evaluating the effects of WL regulations on other wetland species that nest on or near the water, such as the red-necked grebe (Podiceps grisegena) or the black tern (Chlidonias niger). It can also be transferred to other lakes with regulated WL.

\subsection{Probability of Loon Nest Viability According to the Water Level Time Series}

Our results suggest that the 2000RC improved loon nesting conditions. Accordingly, [19] found that loon productivity increased by $95 \%$ in Namakan Reservoir in 2004-2006 compared to 1983-1986, suggesting that the 2000RC improved loon nesting conditions. In Namakan Reservoir, the new conditions imposed by the implementation of the RC allowed the spring peak to occur about 4 QMs sooner than under the 1970RC. Hence, earlier peak WL provide more days with stable WL during the loon nesting season, thereby improving nesting success, giving loons more time to renest if the first nest failed [23].

In Rainy Lake, results from the simulated WL time series suggest that loon nesting conditions would have been very similar under the 1970RC and 2000RC. [19] reported that overall productivity declined between the periods 1983-1986 and 2004-2006, but most of this was attributed to increased nest predation. Unfortunately, reliable data on rates of nest flooding or stranding from 1983-1986 are unavailable to compare to the 2004-2006 period. Predictions obtained with the MEASURED time series suggest, however, that PLNV have decreased in Rainy Lake following the implementation of the 2000RC in 2000. This probably resulted from adverse environmental conditions, namely significant flooding events, which occurred in five years between 2000 and 2012 and brought WL above levels dictated by the 2000RC. These unfavorable environmental conditions were also reflected in the lower and more variable PLNV predicted in Rainy Lake from all the WL time series after 2000.

Our model also showed that the NATURAL time series resulted in more variable and lower PLNV than the 2 regulated time series. Under the NATURAL time series, PLNV would be above 0.5 only once every 3 years on average. Given the lifespan of loons, this could still be sufficient to sustain a loon population [19]. As such, the large lakes of the Rainy-Namakan systems would likely be ecological traps (sensu [32]) for loons under natural water levels, with good adult survival but poor productivity.

With regulated WL, failed nests would have mostly been caused by increasing 
WL early in the nesting season because rising WL are dictated by the RC at that time of the year. On the other hand, under more natural conditions such as those represented by the NATURAL time series, nesting failure would have mostly been caused by decreasing WL throughout the nesting season. The predicted PLNV for the 2000RC suggests that the timing of WL increase under this $\mathrm{RC}$ is appropriate for the majority of nesting loons in both water bodies. Although the PLNV of nests initiated early in the season is lower than that of nests initiated later in the summer, mostly as a consequence of increasing WL at that time, the percentage of early nest initiation is small. Reaching peak WL 1 or 2 QM earlier would nevertheless further improve the PLNV, especially in Rainy Lake. These results also indicate that the more stable WL associated with the RC are more suitable to loon nest viability than the more variable natural conditions.

\subsection{Management Implications}

As water regulations may result in loss or deterioration of wetland habitats, it may also impact wetland birds, such as the common loon, using these habitats. Alterations to RC resulting in changes in the rate of WL rise or fall, even by just a few centimeters per day, may adversely affect loon breeding success, through either nest flooding or exposure to predation by terrestrial predators [19]. Over longer time periods, population size of common loons could possibly be affected. Although we were careful in making valid assumptions about the effect of WL variations on the viability of the common loon nests, our model does not necessarily provide a direct estimate of nesting success. As we mentioned earlier, we have ignored other variables that can affect nesting success (e.g., food availability, water quality, and predation pressure).Incorporation of precise descriptions of nest locations relative to the water edge and a better understanding of loons' nest-raising capacity according to the nature and the slope of the substrate would be required to improve the present model or make it spatially-explicit.

Our model tended to overestimate the probabilities of nest viability compared to available validation data, especially for Rainy Lake. As such, the output of the model for a given plan (here the 2000RC) should be compared to the simulation of the reference plan (here the 1970RC) applied to the same supply scenario. In this way, decisions can be based on the direction and magnitude of change of environmental performance indicators obtained for the alternative plan relative to the baseline reference plan, rather than the absolute value of a performance indicator for a given plan. Used in this manner, the model can accept more uncertainties than it could if it was required to determine if a given target was reached for a given performance indicator. Several alternative plans can then be compared by determining which one results in more favorable conditions relative to the baseline reference plan. The strength of the present model lies in its simplicity and its potential transferability to other water bodies.

Our PLNV model can be used as a performance indicator to evaluate any wa- 
ter regulation plans and help stakeholders in making decisions to mitigate potential detrimental effects on wetland birds. Comparisons can be made between different sets of RC including future projections in any systems where WL data exists or can be modeled. Although human-made reservoirs pose a challenge to loon nesting success, they can provide excellent habitat for nesting loons when carefully controlled [17]. For example, management efforts on Lake Umbagog in New Hampshire targeted a specified water level, which was then stabilized at \pm $0.15 \mathrm{~m}$ during the nesting season. This doubled the number of loon nests fledging chicks per year [33]. Finally, the model can be easily applied to any regulated water body for assessing the performance of WL regulation on nesting success for common loon but it could be used in a similar fashion to assess nesting success in unregulated water bodies in which water level measurements are available. In the near future, new satellite data (for example: SWOT; https://swot.jpl.nasa.gov/) should allow us to obtain observations of water level for lakes larger than $1 \mathrm{~km}^{2}$ at weekly time-step, therefore this loon nesting success model can be applied over very large area, e.g., the whole of North America.

\section{Acknowledgements}

We are deeply indebted to all field assistants and volunteers who assisted in data collection and data management. We are also thankful to Ryan Maki for his advice during the development of the model, and to our colleagues from the Hydrology and Ecohydraulic section of Environment Canada, for their devoted support throughout completion of the present study. This project was funded by the International Joint Commission and Environment and Climate Change Canada.

\section{References}

[1] Wetzel, R.G. (2001) Limnology: Lake and River Ecosystems. Academic Press, San Diego.

[2] Maceina, M.J. and Soballe, D.M. (1990) Wind-Related Limnological Variation in Lake Okeechobee, Florida. Lake Reservoir Management, 6, 93-100. https://doi.org/10.1080/07438149009354699

[3] White, M., Xenopoulos, M., Hogsden, K., Metcalfe, R. and Dillon, P. (2008) Natural Lake Level Fluctuation and Associated Concordance with Water Quality and Aquatic Communities within Small Lakes of the Laurentian Great Lakes Region. Hydrobiologia, 613, 21-31. https://doi.org/10.1007/s10750-008-9469-y

[4] Bond, N.R., Lake, P. and Arthington, A.H. (2008) The Impacts of Drought on Freshwater Ecosystems: An Australian Perspective. Hydrobiologia, 600, 3-16. https://doi.org/10.1007/s10750-008-9326-Z

[5] Wantzen, K.M., Rothhaupt, K.-O., Mörtl, M., Cantonati, M., László, G. and Fischer, P. (2008) Ecological Effects of Water-Level Fluctuations in Lakes: An Urgent Issue. Hydrobiologia, 613, 1-4. https://doi.org/10.1007/s10750-008-9466-1

[6] Zalewski, M. (2008) Ecohydrology-The Use of Ecological and Hydrological Processes for Sustainable Management of Water Resources/Ecohydrologie-La Prise en Compte de Processus Écologiques et Hydrologiques pour la Gestion 
Durable des Ressources en Eau. Hydrological Sciences Journal, 47, 823-832. https://doi.org/10.1080/02626660209492986

[7] Grabowski, T.B. and Isely, J.J. (2007) Effects of Flow Fluctuations on the Spawning Habitat of a Riverine Fish. Southeast Naturalist, 6, 471-478. https://doi.org/10.1656/1528-7092(2007)6[471:EOFFOT]2.0.CO;2

[8] Boers, A.M. and Zedler, J.B. (2008) Stabilized Water Levels and Typha Invasiveness. Wetlands, 28, 676-685. https://doi.org/10.1672/07-223.1

[9] Wallace, J.S., Acreman, M.C. and Sullivan, C.A. (2003) The Sharing of Water between Society and Ecosystems: from Conflict to Catchment-Based Co-Management. Biological Sciences, 358, 2011-2026. https://doi.org/10.1098/rstb.2003.1383

[10] Falkenmark, M. and Rockström, J. (2004) Balancing Water for Humans and Nature: the New Approach in Ecohydrology. Earthscan, London, Sterling.

[11] Arnold, C.L. and Gibbons, C.J. (1996) Impervious Surface Coverage: The Emergence of a Key Environmental Indicator. Journal of the American Planning Association, 62, 243-258. https://doi.org/10.1080/01944369608975688

[12] Andreasen, J.K., O’Neill, R.V., Noss, R. and Slosser, N.C. (2001) Considerations for the Development of a Terrestrial Index of Ecological Integrity. Ecological Indicators, 1, 21-35. https://doi.org/10.1016/S1470-160X(01)00007-3

[13] Foxon, T.J., McIlkenny, G., Gilmour, D., Oltean-Dumbrava, C., Souter, N., Ashley, R., Butler, D., Pearson, P., Jowitt, P. and Moir, J. (2008) Sustainability Criteria for Decision Support in the UK Water Industry. Journal of Environmental Planning and Management, 45, 285-301. https://doi.org/10.1080/09640560220116341

[14] Paillisson, J.-M., Reeber, S. and Marion, L. (2008) Bird Assemblages as Bio-Indicators of Water Regime Management and Hunting Disturbance in Natural Wet Grasslands. Biologial Conservation, 106, 115-127. https://doi.org/10.1016/S0006-3207(01)00239-7

[15] Desgranges, J.-L., Drolet, B., Ingram, J. and Borcard, D. (2006) Modelling Wetland Bird Response to Water Level Changes in the Lake Ontario-St. Lawrence River Hydrosystem. Environmental Monitoring Assessment, 113, 329-365. https://doi.org/10.1007/s10661-005-9087-3

[16] Evers, D.C. (2006) Loons as Indicators of Aquatic Integrity. Environmental Bioindicators, $1,18-21$.

[17] Mcintyre, J.W. (1988) The Common Loon: Spirit of Northern Lakes. University of Minnesota Press, Minneapolis.

[18] Vlietstra, L.S. and Paruk, J.D. (1997) Predation Attempts on Incubating Common Loons, Gavia immer, and the Significance of Shoreline Nesting. The Canadian Field-Naturalist, 111, 656-657.

[19] Windels, S.K., Beever, E.A., Paruk, J.D., Brinkman, A.R., Fox, J.E., MacNulty, C.C., Evers, D.C., Siegel, L.S. and Osborne, D.C. (2013) Effects of Water-Level Management on Nesting Success of Common Loons. Journal of Wildlife Management, 77, 1-13. https://doi.org/10.1002/jwmg.608

[20] McIntyre, J.W. (1975) Biology and Behavior of the Common Loon (Gavia immer) with Reference to Its Adaptability in a Man-Altered Environment. University of Minnesota Press, Minneapolis.

[21] Barr, J.F. (1979) Ecology of the Common Loon in a Contaminated Watershed. In: Sutcliffe, S.A., Ed., Proceedings of the 2 nd North American Conference on Common Loon Research and Management, National Audubon Society, New York, 65-69. 
[22] Fair, J.S. (1979) Water Level Fluctuation and Common Loon Nest Failure. In: Sutcliffe, S.A., Ed., Proceedings of the 2 nd North American Conference on Common Loon Research and Management, National Audubon Society, New York, 57-63.

[23] Gutreuter, S., Windels, S.K. and Maki, R. (2013) Development of Models to Assess Effects of Water-Level Fluctuations on Reproductive Success of Common Loons. Project Completion Report to the International Joint Commission, U.S. Geological Survey, La Crosse.

[24] Evers, D.C. (2007) Status Assessment and Conservation Plan for the Common Loon in North America. Technical Report, U.S. Fish and Wildlife Service, Hadley.

[25] Kallemeyn, L.W., Holmberg, K.L., Perry, J.A. and Odde, B.Y. (2003) Aquatic Synthesis for Voyageurs National Park: USGS. Columbia Environmental Research Center, International Falls.

[26] Thompson, A.F. (2013) Rainy and Namakan Hydrologic Response Model Documentation. Prepared for the Evaluation of the International Joint Commission 2000 Order for Rainy and Namakan Lakes and Rainy River. Environment Canada, Burlington.

[27] Morin, J., Bachand, M., Hénault-Richard, J. and Martin, S. (2016) Modeling the Rainy Lake and Namakan Reservoir Ecosystem Response to Water Level Regulation. Scientific Report SR-110 MSC Québec-Hydrology and Ecohydraulic Section, Environment and Climate Change Canada, Prepared for the International Joint Commission Study on Rainy Lake and Namakan Reservoir, Québec.

[28] Bird Studies Canada (BSC) (2014) Project Nest Watch. http://www.bsc-eoc.org

[29] Rousseu, F. and Drolet, B. (n.d.) The Nesting Phenology of Birds in Canada CWS Technical Report Series. Canadian Wildlife Services, Québec.

[30] Campbell, R.W., Preston, M.I., Van Damme, L.M., Evers, D.C., Roberts, A. and Andrews, K. (2008) Featured Species-Common Loon. Wildlife Afield Journal, 5, 54-146.

[31] Natural Heritage and Endangered Species Program (2007) Massachusetts Forestry Conservation Management Practices for Common Loons, Natural Heritage and Endangered Species Program, Massachusetts Division of Fisheries and Wildlife, Westborough.

[32] Battin, J. (2004) When Good Animals Love Bad Habitats: Ecological Traps and the Conservation of Animal Populations. Conservation Biology, 18, 1482-1491. https://doi.org/10.1111/j.1523-1739.2004.00417.x

[33] Fair, J. and Poirier, B.M. (1993) Managing for Common Loons on Hydroelectric Project Reservoirs in Northern New England. In: Morse, L., Stockwell, S. and Pokras, M., Eds., The Loon and Its Ecosystem, Proceedings of the 1992 North American Loon Conference, U.S. Department of Interior, Fish and Wildlife Services, Concord. 